\title{
RESOURCE OPTIMIZATION BY SIMULATION TECHNIQUE IN FOOD LOGISTICS
}

\author{
É. HAJNAL ${ }^{1 *}$ - G. ALMÁSY² - K. Kollár-Hunek ${ }^{3}-$ G. Kollár ${ }^{1}$ \\ ${ }^{1}$ Postharvest Department, Corvinus University of Budapest. \\ H-1118 Budapest, Ménesi út 45, Hungary \\ (Phone:+36/20/466-5541) \\ ${ }^{2}$ Department of Process Engineering, University of Veszprém. \\ H-8200 Veszprém, Egyetem u. 10, Hungary \\ (Phone:+36/88/624-000) \\ ${ }^{3}$ Department of General and Analytical Chemistry, Budapest University of Technology and \\ Economics. H-1114 Budapest, Szt. Gellért tér 4. Hungary \\ (Phone:+36/1/463-3174) \\ *Corresponding author \\ e-mail: hajnal.eva@axing.hu \\ (Received 27 $7^{\text {th }}$ Feb 2007; accepted $15^{\text {th }}$ May 2007)
}

\begin{abstract}
Any activity that receives inputs and convert them to outputs can be considered as a process. Essentially the same model equations are used in the theory of chemical, biochemical, nuclear, mechanical, or other process engineering. The goal of our researcher group has been to identify the processes, a network of processes, process variables and process equations in food logistics. In our paper we introduce how process building, simulation run and optimization can be carried out in a Food Distribution Centre with a message-based discrete event simulation software. We identify the parameters of the general equations of the discrete event models, with two corresponding examples. We also introduce how simulation can work as a decision supporting tool in the hand of company management, and how can a wrong decision affect the extent of air pollution coming out from cooling vehicles.
\end{abstract}

Keywords: Food logistics; discrete event models; simulation technique; queuing, air pollution.

\section{Introduction}

Distribution centres (DC) are important elements of the food supply chain. In a DC there are core processes which are essential for the success of an organization and additional processes. These processes together form a process network.

In business, a common goal is to optimize a system with respect to the highest amount of products using the least amount of resources and time. To find the processes to be optimized, we should do process mapping ranging over the whole organization to define and document all processes necessary for the normal operation. Connections of processes only after this mapping can be defined, as well as the process network described.

After the process network is known, the whole process can be decomposed into subprocesses, where the output of one subprocess is the input of one or more other subprocesses. It is important that every subprocess's contribution to the whole service should be measurable. This forms a distribution chain, where time-based approach is dominating. Delivery times of subprocesses related to the whole process sum up. [1] 


\section{Review of literature}

We can simplify and define the core process in a DC, which shows Figure 1.

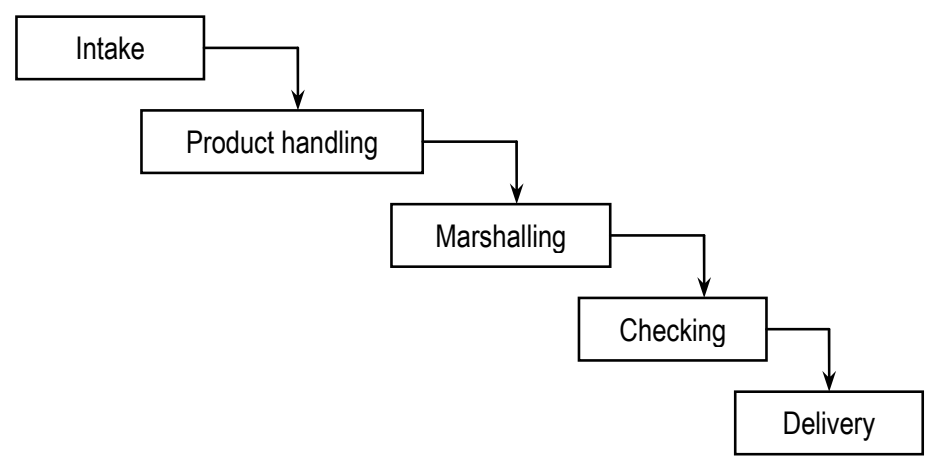

Figure 1. Core process in a DC [2]

The efficiency of processes can be measured with the process specific Key Performance Indicators. These indicators are very important in the case of the initial state examination and during process change monitoring. [3] Processes - defined during process mapping - should be recorded and modelled.

\section{Modelling and simulation}

In a qualified sense we can call modelling mathematical model building. Models are simplified versions of real life processes or systems, which enhance their relevant features. This definition shows that models can never entirely substitute real life processes. In many models, we are interested in the time required for an item to move from one end of the model to the other. Examining processes as a whole unit, one of the most important performance indicator is cycle time, which is necessary to transform inputs to outputs.

Series of experiments carried out on the constructed model is simulation. During simulation we simulate real life events by experimental methods. We examine the effect of different inputs, the disturbing signs upon the formed state variables, and also the outputs generally while we are seeking optimal solutions. [4]

Continuous time models can be described by functions that are continuous in their time variable. Values reflect the state of the modelled system at any particular time, and simulated time can advance evenly from one time step to the next.

Discrete event models track individual and unique entities, known as items. These items change state as event occurs in the simulation. The state of the model changes only when those events occur; the mere passing of time has no direct effect. For a discrete event model, simulated time advances from one event to the next and it is unlikely that the time between events will be equal. [5]

It is important that a system can be modelled in any number of different ways, depending on what you want to accomplish. In general, how you model the system depends on the purpose of the model: what type, level, and accuracy of the information you want to gather.

It's advisable to use such a simulation tool whose model-descriptive language can be fitted to the modeller's needs, while model running is managed by an executive system which fits the computer representation. [6] 
To model a warehouse operation, we used message-based discrete event simulation software (Extend), and our own programs written for Matlab in C language, or for MS Excel in Visual Basic for Excel (VBA).

The architecture of Extend based on a messaging system. Instead of a centrally located simulation program executing subroutines based on simulation data, this architecture sends messages from one simulation block to another. The central simulation engine performs only event scheduling and selection. The bulk of the simulation execution is performed by blocks sending messages to one another. [7]

\section{Almásy's postulates and equations of discrete process models}

According to Almásy's postulates [8], processes may be described by operation models, composed processes by operation models of the subprocesses and transfer models between the subprocesses. We consider all processes possible subprocesses of a more general process, what means, it is enough to discuss process models since they include subprocess models, as well.

In general, to simulate both the operation and transfer models, the knowledge of a lot of state-property functions is needed. These functions are generally called constitutive equations.

Considering the food logistics processes we deal with in our paper, we restrict the following statements to the description of discrete time-process that is having discrete variables.

According to Postulate 1, actual properties of a process depending on material quality, are depending only on their actual entity content.

According to Postulate 2, actual changes of processes are depending only on the actual state of the given process.

As a corollary of Postulate 3, the sum of streams is given by the sum of connected streams in any arbitrary point of the process space, regardless of the direction of the streams.

It is necessary to take into account Postulate 6 for the model of process decomposition; it means the process should be decomposed into subprocesses of the same independent variables and those of the same time variable.

The operation model has to fulfil Postulate 9. (E.g. the operation model should be dimensionally correct.)

The solution of the composed models will be given by the time sum of the simultaneous equation system of each operation model and of each stream model, including their initial and boundary conditions. (It requires the fulfilment of Postulates 7 and 8 )

The operation model - of course - depends on the material properties, too, but they are considered as properties of the functions describing the model, so we don't discuss it in details. But we assume - according to Postulates 4 and 5 - that the functions that connect potentials and entity contents are known one-to-one (invertible) functions.

To simulate a process, the model has to solve the following problem:

It is necessary to determine the potentials and driving forces between the connected environmental points, based on the entity content of the process and its environmental points, and then to determine the entity content corresponding to a $\Delta t$ time step, using the sum of the potentials and driving forces with respect to the process variables.

Describing an operation model by its equations in a discrete process space, we have to determine the $h_{j}\left(\boldsymbol{e}_{i}, t\right)$ potentials for each $\boldsymbol{i}$ subprocess toward or from the $\boldsymbol{j}$ subprocesses and the stream rates of each $\boldsymbol{i}$ subprocess toward or from the environment 
denoted by $\mathbf{v}_{i}(t)$. Using the notation above, we get equation (1), the $\Delta \mathbf{e}_{i}(t)$ entity change for the $\Delta t$ time step:

$$
\Delta \mathbf{e}_{i}(t)=\left(\sum_{j \in I} \mathbf{L}_{i, j}\left(\mathrm{~h}_{j}\left(\mathbf{e}_{i}(t)\right)\right)+\mathbf{v}_{i}(t)\right) \cdot \Delta t \quad \forall \boldsymbol{i} \in I \quad t \in T
$$

The first term on the right side (a sum regarding all subprocesses) is defined so that the stream is zero between subprocesses having no contact, or in the case $\boldsymbol{i}=\boldsymbol{j}$. The entity increase of each entity component in any process space element $\boldsymbol{i}$ must be the sum of all entering-leaving streams $\boldsymbol{j}$ connected to it.

Equation (2) defines the velocity of entity-transfer between the subprocesses $\boldsymbol{i}$ and $\boldsymbol{j}$ in case of discrete-time processes having discrete process variables:

$$
\begin{aligned}
\mathbf{r}_{i, j}(t)=\left(\frac{\Delta \mathbf{e}_{j}(t)}{\Delta t}\right)_{i=\text { const }}=\left(\frac{\left(\mathbf{e}_{j}(t+\Delta t)-\mathbf{e}_{j}(t)\right)}{\Delta t}\right)_{i=\text { const }} \equiv-\left(\frac{\left(\mathbf{e}_{i}(t+\Delta t)-\mathbf{e}_{i}(t)\right)}{\Delta t}\right)_{j=\text { const }}=-\left(\frac{\Delta \mathbf{e}_{i}(t)}{\Delta t}\right)_{j=\text { const }}^{=}-\mathbf{r}_{j, i}(t) \\
\forall i \boldsymbol{i}, \boldsymbol{j} \in I
\end{aligned}
$$

As one can see, the velocity in Equation 2 is defined by the partial difference quotients of $\boldsymbol{e}_{\boldsymbol{i}}$ or $\boldsymbol{e}_{\boldsymbol{j}}$ with respect to the time; according to this, the dimension of $\mathbf{r}$ is entity/time. This definition contains also the fulfilling of Postulate 3.

\section{Definitions}

QM Quality Management

DC Distribution Centre

KPI Key Performance Indicator

AMB Ambient

CHL Chilled

FRZ Frozen

WH Warehouse

QL model Queue length model

FIFO First In First Out

HR model Human Resource model

WHK Warehouse Keeper

RTD Reach Truck Driver

PPTD Pedestrian Pallet Truck Driver

IPP Income per Pallet

InPalNum Number of pallets processed

cWHK Cost of one WHK

WHKnum Number of WHKs

cRTD Cost of one RTD

RTDnum Number of RTDs

cPPTD Cost of one PPTD

PPTDnum Number of PPTDs

$\mathrm{e}_{i}(t) \quad$ time dependent distribution of an entity

$\mathrm{h}\left(\mathbf{e}_{i}(t)\right) \quad$ potential in a discrete process

$\boldsymbol{i}$ or $\boldsymbol{j}$ a discrete process variable vector

$I$ the set of discrete proc. variable vectors

$M \quad$ the set of entities 


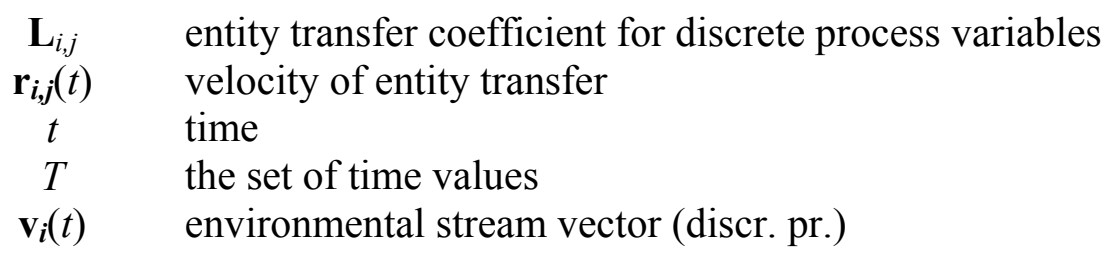

\section{Materials and Methods}

We modelled processes of a food distribution centre in which there are chambers for products at three different temperature ranges: ambient (AMB), chilled (CHL) and frozen (FRZ). We modelled the inbound delivery of products, transported by trucks. All products are stored on full pallets, and each chamber has the same number of docks. Warehouse (WH) operations are quite complex, hence during building process models we applied simplifications to make models more transparent, and also to shorten running times. These simplifications are not affecting the correctness of the results because the eliminated information does not bear upon high importance to the original questions of our case studies.

\section{Queue length (QL) study}

\section{Extend model}

In the first study, with Almásy's model and also with the help of Extend simulation software, we examined inbound delivery in a warehouse with the initial data detailed below. A valid question in WH daily operation is whether there is any effect on truck waiting times and queue length if ambient foodstuff can be unloaded also at possibly free chilled docks or not. We studied these two options parallel.

Incoming items:

Trucks carrying food in 3 temperature ranges (ambient, chilled, frozen), arriving in exponential distribution with the mean of 5 minutes (interarrival time);

$\mathrm{WH} /$ food type distribution:

$50 \%$ ambient, $30 \%$ chilled, $20 \%$ frozen in random distribution;

Priority rule:

version1 QL model's trucks can dock only at the same temperature docks;

version2 QL model's AMB trucks can dock also at CHL docks when there is no CHL truck waiting in the CHL queue, while FRZ trucks can dock only at FRZ docks;

Number of docks: 5 /each WH type;

Resources: unlimited;

Unloading time: $\quad 50 \mathrm{~min} /$ truck;

Run length: $\quad 24$ hours;

Number of runs: 4 .

\section{Almásy's model}

Entities: trucks (AMB, CHL, FRZ)

Subprocesses: waiting (1), docking (2), intake (3)

Environmental stream: arriving, leaving

- the entity-stream of leaving has no effect on the process

- the sum of entity streams from "arriving" environment is given by the exponential distribution; the individual entity streams are given by random 
distribution, dividing the sum of streams into AMB, CHL, FRZ streams toward Subprocess (1)

- the Subprocesses (2) and (3) have no (direct) contact with the "arriving" environment.

The entity streams from Subprocess (1) toward Subprocess (2) are given by the FIFO queueing and in version 2 also by the special bounds for AMB.

Subprocess (3) can also be integrated into Subprocess (2) by a 40 min processing time

\section{Human Resource (HR) study}

\section{Extend model}

In our second study we examined the human resource question of inbound delivery in an ambient warehouse, and we would like to find out what is the optimal number of Warehouse-keepers (WHK), Reach truck drivers (RTD) and Pedestrian pallet truck drivers (PPTD) to reach the maximum profit.

Incoming items:

Trucks carrying ambient foodstuffs, arriving just like in the QL model (exponential distribution, mean: 5 minutes, $50 \%$ random $\mathrm{AMB}$ );

Priority rule:

Every worker can do his own tasks plus tasks that require less skills (high - PC knowledge, medium - RT driving license, low - PPT driving license). Administration can do only WHK, pallet intake can do RTD and WHK, and pallet unloading can do PPTD, RTD and WHK. From the resource pools, the model always chooses workers with higher skills to do valuable jobs with higher priority;

Number of docks: 5 /each WH type;

Unloading time: $90 \mathrm{~min} /($ truck/worker); Administration time: $15 \mathrm{~min} /($ truck/worker); Intake time: $3 \mathrm{~min} /$ pallet (30pallets/truck) $=90 \mathrm{~min} /($ truck/worker).

Run length: $\quad 24$ hours;

Number of runs: For Almásy's model it is discussed at the corresponding model specification. For Extend model checks convergence after 50 cases and terminate if best and worst are within 0.95 level;

Objective function: Our model has parameters that are specified and shouldn't vary, while some parameters could vary and change the efficiency of the model. Because none of the parameters can be varied in our simplified model except the number of WHKs, RTDs and PPTDs, our objective function is given as follows in equation (3):

$$
\begin{gathered}
\text { MaxProfit }= \\
\text { IPP*InPalNum-cWHK*WHKnum-cRTD*RTDnum-csPPTD*PPTDnum }
\end{gathered}
$$

During optimization we varied the number of WHKs between 1 and 5, RTDs and PPTDs between 5 and 15;

Simplifications:

- Doing the same job takes the same time for any workers;

- Workers are doing their jobs only at AMB WH and only inbound delivery;

- The 24-hour run time is divided into 8-hour or 4-hour shifts with respect to the workers.

Almásy's model

Entities: trucks (AMB), Human resources (WHK, RTD, PPTD)

Subprocesses: waiting(1), docking(2), unloading(3), administration(4), intake(5)

\footnotetext{
APPLIED ECOLOGY AND ENVIRONMENTAL RESEARCH 5(1): 189-200

http://www.ecology.uni-corvinus.hu • ISSN 15891623

(C) 2007, Penkala Bt., Budapest, Hungary
} 
Environmental stream: arriving, leaving (for trucks)

- the entity-stream of leaving has no effect on the process

- the sum of entity streams from "arriving" environment is given by the exponential (mean=10 $\mathrm{min}$ ) interarrival time, toward Subprocess (1)

- the other Subprocesses have no (direct) contact with the "arriving" environment.

The entity streams from Subprocess (1) toward Subprocess (2) are given by the FIFO queueing, and by scheduling of human resources.

The entity streams between the Subprocesses (2) $\rightarrow(3),(3) \rightarrow(4)$ and (4) $\rightarrow(5)$ are given by the scheduling of human resources.

\section{Results}

\section{Queue length $(Q L)$ study}

The cooling vehicles are waiting for their turn at the parking place with working engine. Each of them acts as an individual air pollutant. With simulation experiments we would like to know how truck waiting times change in case version 1 and version 2 and whether can it cause serious overdose of air pollutants, coming from cooling vehicles or not. In this study we considered unlimited resources that can satisfy the condition keeping $50 \mathrm{~min} /$ truck unloading time. This unloading time value is a quite good industrial average. We investigated the effect of scheduling human resources in our second study.

\section{Almásy's model}

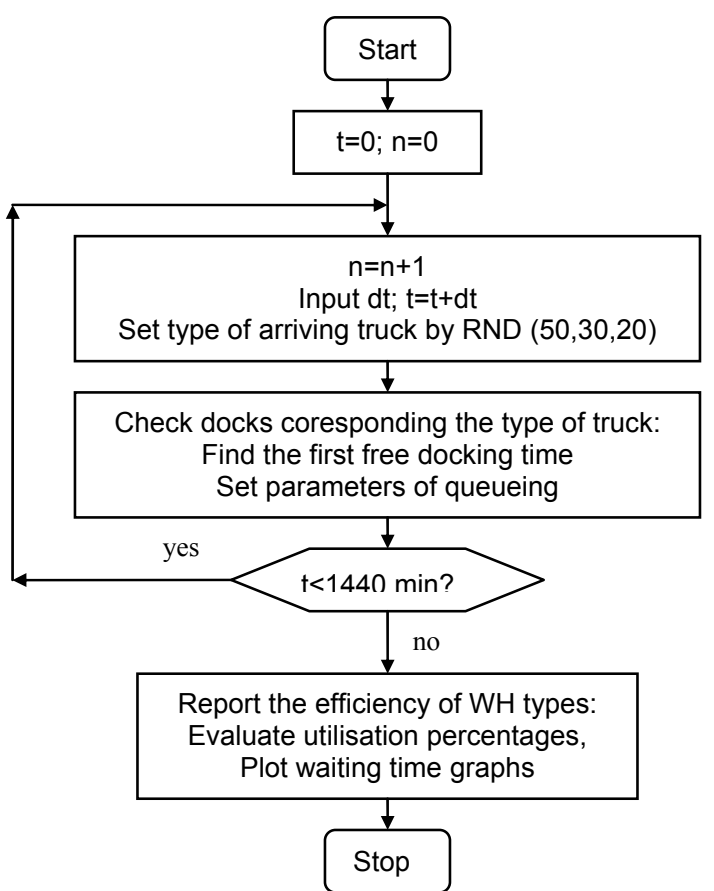

Figure 2. Block diagram of $Q L$ model
The block diagram for the solution of the process equations is given in Figure 2; some of the results are shown in Figure 3. Results are numerically detailed in Table 1

If we want to simulate more than one 24-hour-shift by this model, at the beginning of the $\mathrm{k}^{\text {th }}$ shift $(\mathrm{k}>1)$, after setting back the time variable to $\mathrm{t}=0$, we have to initialise the $\mathrm{n}$ variable taking into account the remained trucks from the previous shift. This can be made by giving up the condition that "arriving" environment is given only by the exponential and random distribution. There is also an initial condition to each shift, namely, there are given the remained trucks to each dock together with their waiting-time vectors. 

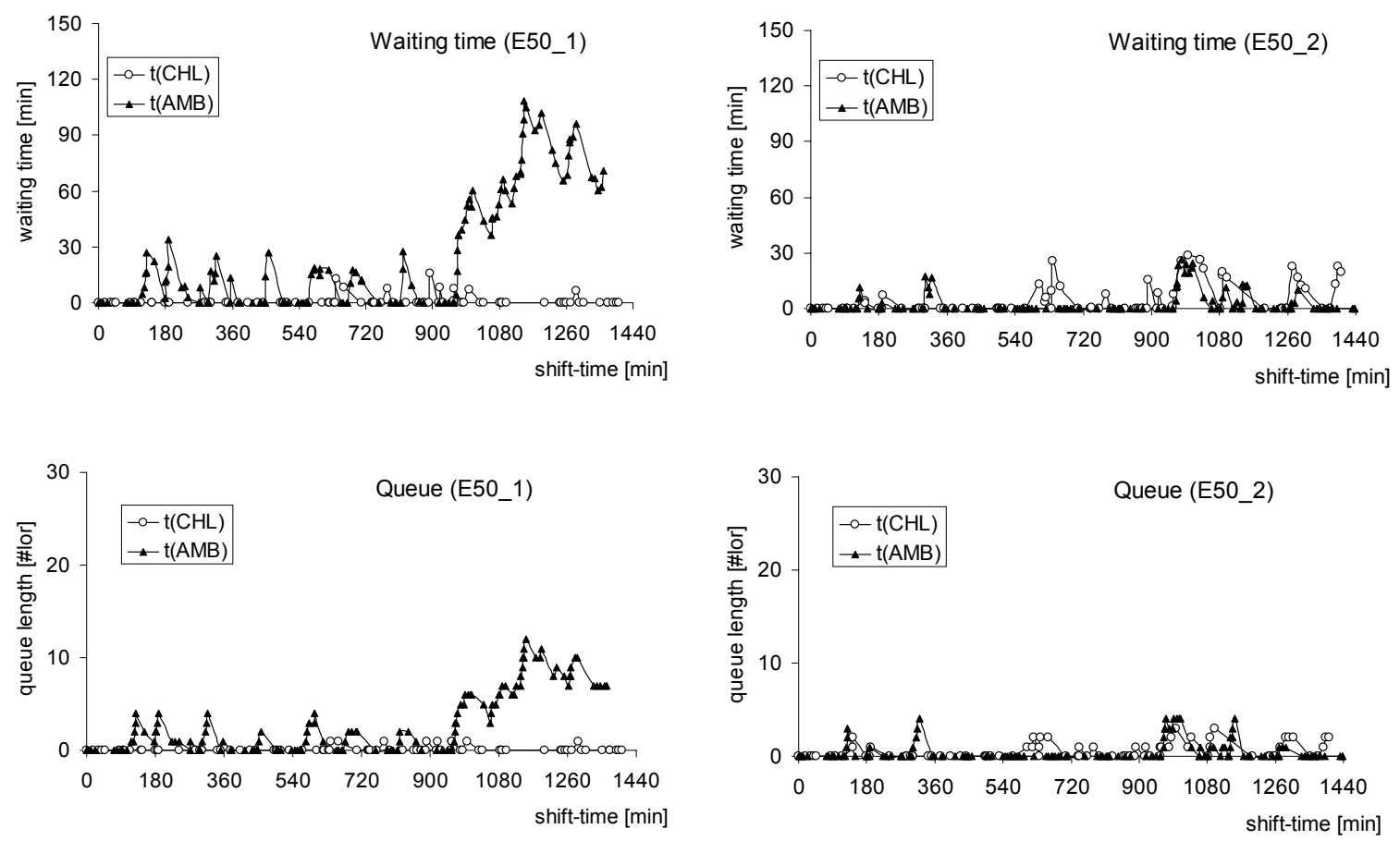

Figure 3. Queue length and waiting time of Intake version 1 (E50_1) and version 2 (E50_2) by Almásy's model and Extend (run 1)

\section{Extend model}

Figure 4 shows the QL model set up from blocks. The processing itself goes on at docks. Figure 5 shows the details of the main model's Intake version 1 and Intake version 2 blocks, which are hierarchic blocks in the system. The only difference between two subprocesses is: version 2 allows ambient trucks - with lower priority - to dock in at possibly free chilled docks.

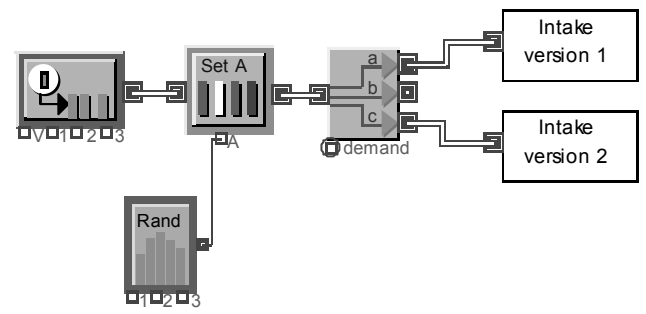

Figure 4. QL model [Extend simulation software]

The generator block generates items with an interarrival time according to an exponential distribution, and then we set the warehouse type as an attribute of the generated items. We analysed version 1 and version2 parallel; to do this we should equally divide every incoming item (with all of their attributes), and derive them to the next sub-processes. We work with FIFO queueing discipline for ambient, chilled and frozen operations. The model calculates the average queue-length, average wait-time, and utilization of the queue, and counts trucks leaving the docks. 

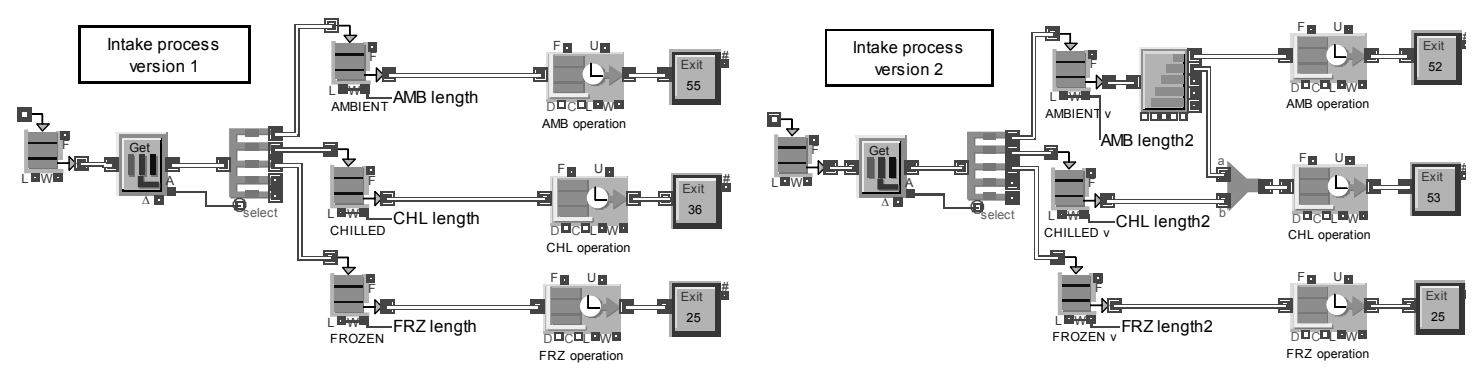

Figure 5. QL model Version1 and Version2 subprocesses [Extend simulation software]

Although theoretically it seems to be not trivial to reach better result in case version2 model, there are major differences on truck waiting times and queue length if ambient foodstuffs can be unloaded also at chilled docks. When the ambient trucks can dock only at AMB docks, the queue length and the truck waiting time will start to increase in the last third of the simulation time, and after the 24-hour shift, there will remain trucks stuck in the queue. The utilisation of docks is equalized in case version2; the average wait and the maximum wait have also decreased. The graphs and the numerical results are same as it was in case of Almásy's model (see Figure 3 and Table 1).

Table 1. Numerical results of Intake versions 1 and 2 by Almásy and Extend (1-4 runs)

\begin{tabular}{ccccccc}
\hline Run & Truck & AMB & CHL & FRZ & Sum & Util(AC)\% \\
\hline \multirow{2}{*}{1} & arrived & 136 & 84 & 44 & 264 & \\
& Intake v1 & 125 & 82 & 44 & 251 & $94 \%$ \\
& Intake v2 & 132 & 81 & 44 & 257 & $97 \%$ \\
\hline \multirow{2}{*}{2} & arrived & 143 & 89 & 48 & 280 & \\
& Intake v1 & 137 & 88 & 47 & 272 & $97 \%$ \\
& Intake v2 & 138 & 87 & 47 & 272 & $97 \%$ \\
\hline \multirow{2}{*}{3} & arrived & 147 & 93 & 48 & 288 & \\
& Intake v1 & 138 & 92 & 48 & 278 & $96 \%$ \\
& Intake v2 & 143 & 92 & 48 & 283 & $98 \%$ \\
\hline \multirow{2}{*}{4} & arrived & 156 & 94 & 53 & 303 & \\
& Intake v1 & 137 & 93 & 50 & 280 & $92 \%$ \\
& Intake v2 & 150 & 93 & 50 & 293 & $97 \%$ \\
\hline
\end{tabular}

\section{Human Resource (HR) study}

In this study our goal was to investigate whether a reasonable schedule of human resources could solve the queuing problem of AMB trucks without any changeover to the CHL docks. The individual WHK, RTD and PPTD workers work in flexible shifts. During the 24 hour simulation time - after the transient period - the number of workers can vary between wide ranges.

\section{Almásy's model}

A good schedule of human resources made it possible to serve all the incoming AMB trucks at the AMB docks. The average of inbound delivery time was $44.7 \mathrm{~min}$ in the case of 135 arrived trucks. Figure 6 shows the transient part of HR schedule, and in Figure 7 one can see the number of active RTD workers at the moment. 


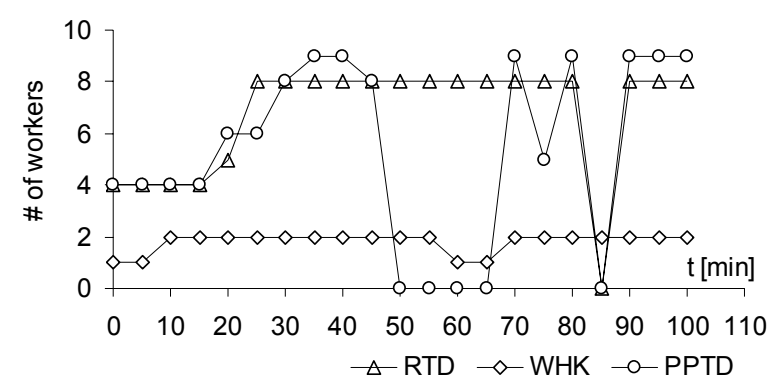

Figure 6. Transient part of HR schedule

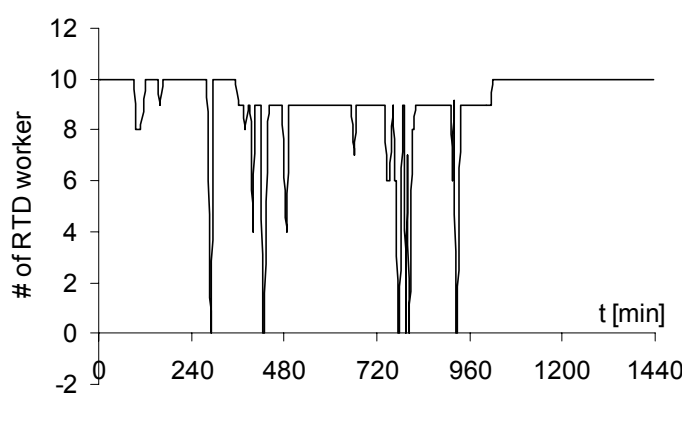

Figure 7. Occupied RTD workers
In Table 2 we compare the results of the models discussed. The highest MaxProfit belongs to Almásy's model-version.
Table 2. Results of Almásy's and Extend models

\begin{tabular}{ccccccc} 
& arrived & intake & WHK & RTD & PPTD & MaxProfit \\
\hline Almásy & 135 & 135 & 2 & 9 & 9,5 & $858340 \mathrm{Ft}$ \\
\hline Extend & 135 & 133 & 2 & 11 & 11 & $819500 \mathrm{Ft}$ \\
\hline
\end{tabular}

\section{Extend model}

Figure 8 shows HR model, which contains four hierarchical blocks: Docking, Pal.unloading, Administration and Pal.intake. These blocks are shown in Figure 9 and in Figure 10.

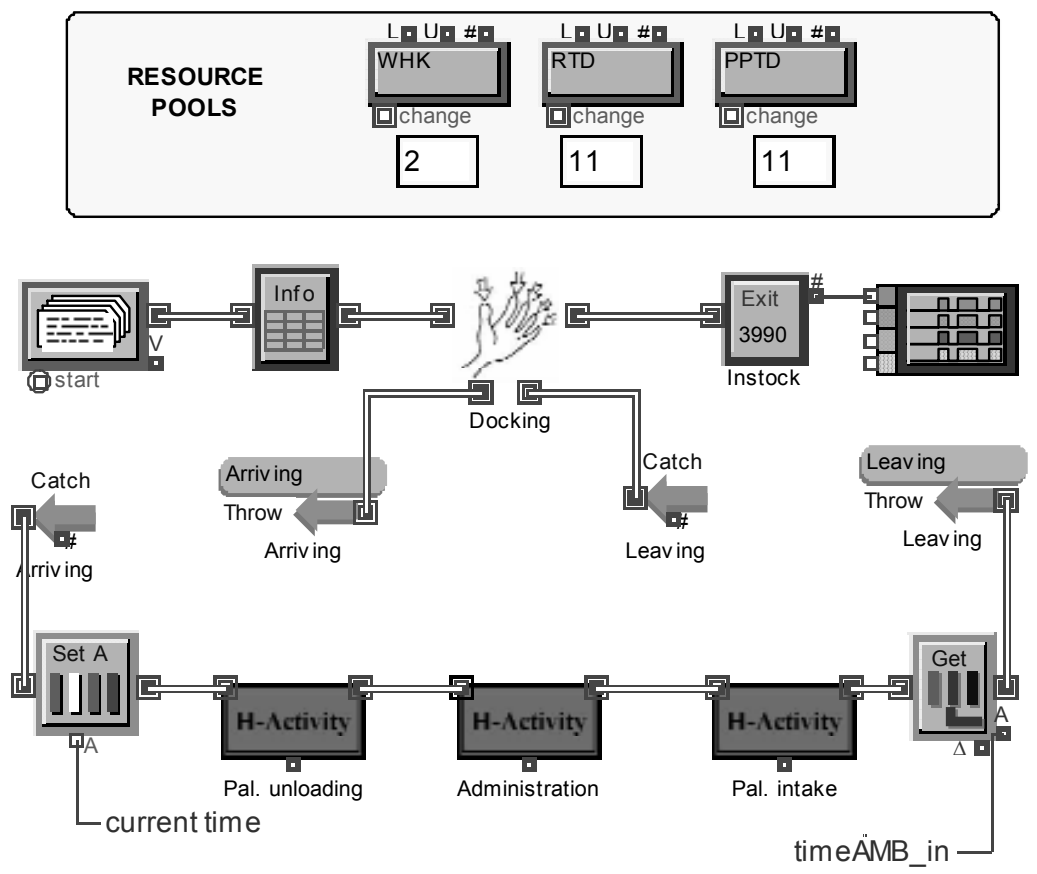

Figure 8. HR model [Extend simulation software] 


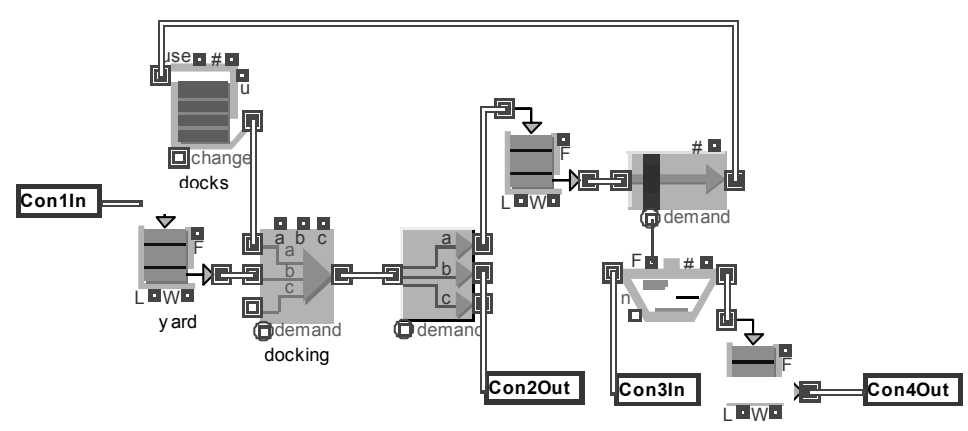

Figure 9. HR model-Docking subprocess [Extend simulation software]

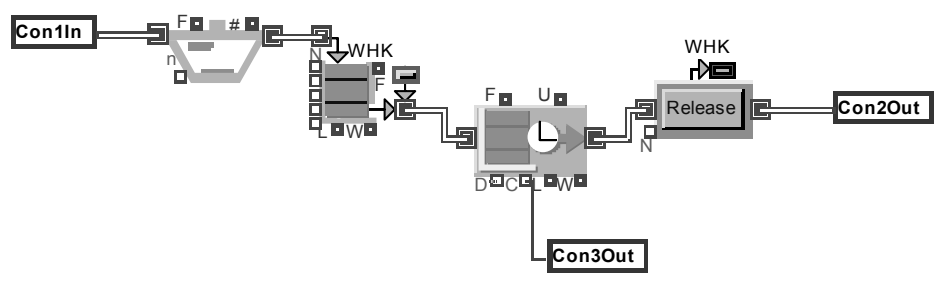

Figure 10. HR model-Activity multiple subprocess [Extend simulation software]

In most cases the optimizer would like to minimize the cost or maximize the profit to get a benefit from optimization.

We found the optimum at WHKnum=2, RTDnum=11 and PPTDnum=11 with the convergence of 99\%. The max Profit and Convergence plot is shown in Figure 11.

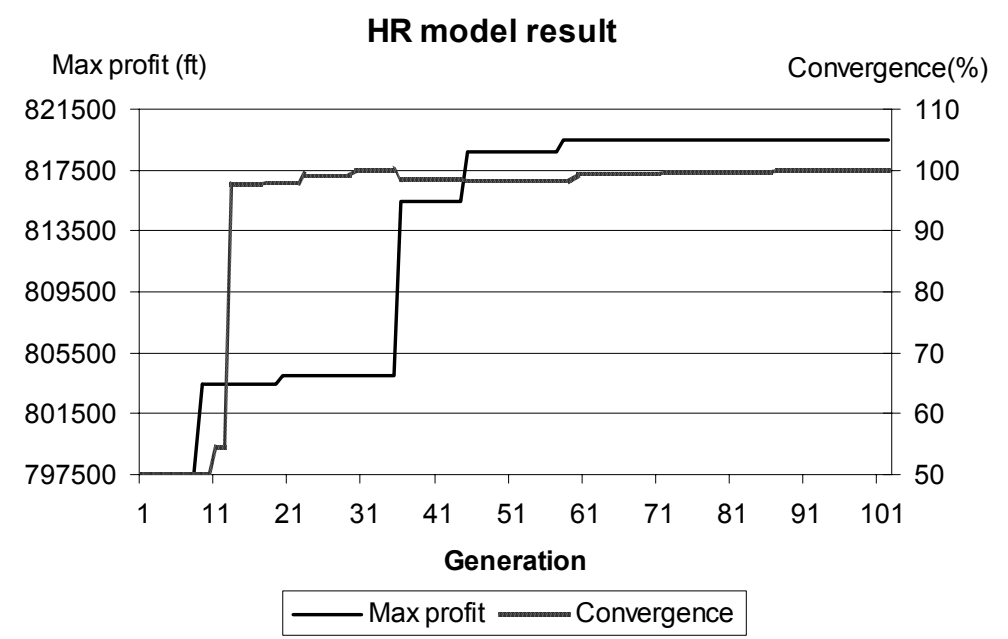

Figure 11. HR model result by Extend

\section{Discussion}

Any activity that receives inputs and converts them to outputs can be considered as a process - this is a highlighted concept in Quality Management (QM) standards. From the point of view of an efficient QM, the previous statement means that every industrial company is a network (system) of processes. 
The basis of process simulation is a very detailed process mapping. Processes should be well defined, documented, up to date, and the key performance indicators, which describe the process, also should be known. During simulation these indicators will show the differences of each setup. Building a model allows us to optimise logistics processes by using computer experiments rather than costly plant time.

In this paper we have examined normal daily warehouse operational problems like directing trucks to docks or optimising human resources. As the cooling vehicles are waiting for their turn at the parking place with working engine, they act as an individual air pollutant. From environmental point of view we found, that to reach the same result (intake all pallets) optimising human resources seems better, than optimizing truck routes. In this case none of CHL trucks should wait at the CHL docks, because previously AMB trucks were directed there.

In our paper we demonstrated how computer simulation works as a decisionsupporting tool in the hand of company management. With simulation experiments we verified that a wrong operational decision can cause serious overdose of air pollutants, because of increased truck waiting times.

Acknowledgements. The authors wish to express their gratitude to Gábor Tóth (Axing Ltd).

\section{REFERENCES}

[1] Tenner, A. R.; I. J. DeToro L.: BPR (in Hungarian), Müszaki Könyvkiadó, Budapest, 1998.

[2] Hajnal, É. and G. Kollár (2005): Optimization of Food Logistic Processes by Simulation Technique. Special issue of Hungarian Journal of Industrial Chemistry: Computer Aided Process Engineering. Vol 33. pp. 105-111.

[3] Hajnal É., Kollár G.: Process optimalisation and monitoring in logistics (in Hungarian), Proc. of conf. MKN 2004, Veszprém, Hungary.

[4] Benyó Z., Szücs B.: Folyamatszabályozás, BME-SOTE-ÁOTE Orvosbiológiai Mérnöki Szak Egyetemi Jegyzet, Budapest, 1995.

[5] Diamond, B.: Simulation overview, Imagine That Inc, 2002, www.imaginethatinc.com

[6] Jávor A.: Diszkrét szimuláció, SZIF-UNIVERSITAS Kft., Győr, 2000.

[7] Krahl D., Lamperti J. S.: A message-based discrete event simulation architecture, Proceedings of the 1997 Winter Simulation Conference ed. S. Andradóttir, K.J. Healy, D.H. Withers and B.L. Nelson.

[8] Almásy, G.A. and K. Kollár-Hunek (2005): Basic principles of process modelling. Special issue of Hungarian Journal of Industrial Chemistry: Computer Aided Process Engineering. Vol 33. pp. 1-9. 